\title{
Resistência anti-helmíntica em nematoides gastrintestinais de pequenos ruminantes: avanços e limitações para seu diagnóstico ${ }^{1}$
}

\author{
Fernanda S. Fortes ${ }^{2 *}$ e Marcelo B. Molento ${ }^{2}$
}

\begin{abstract}
Fortes F.S. \& Molento M.B. 2013. [Anthelmintic resistance in gastrointestinal nematodes of small ruminants: advances and limitations for diagnosis.] Resistência anti-helmíntica em nematoides gastrintestinais de pequenos ruminantes: avanços e limitações para seu diagnóstico. Pesquisa Veterinária Brasileira 33(12):1391-1402. Laboratório de Doenças Parasitárias, Universidade Federal do Paraná, Rua dos Funcionários 1540, Curitiba, PR 80035-050, Brazil. E-mail: fortesfs@gmail.com

The selection and growing spread of resistant nematodes to the most commonly used anthelmintics, benzimidazoles (BZs), imidazoles and macrocyclic lactones (MLs), constitutes a serious obstacle of small ruminants production worldwide. The use of efficient and sensitive methods for detection and monitoring of anthelmintic resistance in the field becomes urgent, especially for the BZs and MLs groups due to its frequent resistant reports. Obtaining an early and accurate diagnosis of resistance is extremely important to aid decision-making regarding parasite control programs, with the objective to preserve the lifespan of existing products, and to limit the development of resistance in nematode populations. The in vivo tests and the more recent in vitro tests have been developed for the detection of nematode resistant to the major anthelmintic groups. However, the availability of validated in vitro tests and its practical use is still very limited. Although the faecal egg-count reduction test (FECRT, in vivo - indirect) is the primary method of choice for the detection of resistance in the field it has being criticized for its results and is receiving significant modifications. Moreover, the development of molecular techniques from genomic changes have generated considerable advances in this research area, with the use of mutations at codons 167, 198 and 200 of $\beta$-tubulin gene as the main SNPs (single nucleotide polymorphisms) associated with BZs resistance. This review aims to discuss the available diagnostic methods for the detection of anthelmintic resistance in nematodes of small ruminants, highlighting key developments and obstacles to its use in the laboratory and in the field.
\end{abstract}

INDEX TERMS: Anthelmintics, anthelmintic resistance, nematoides gastrintestinais, Haemonchus contortus, sheep, in vivo tests, in vitro tests, efficacy.

RESUMO.- A seleção e a crescente disseminação de nematoides resistentes aos anti-helmínticos mais comumente utilizados, benzimidazóis (BZs), imidazotiazóis e lactonas macrocíclicas (LMs), constituem um sério entrave na produção de pequenos ruminantes em todo o mundo. 0 uso de métodos eficientes e sensíveis para a detecção e o monitoramento da resistência anti-helmíntica no campo torna-se urgente, especialmente para os grupos de BZs e LMs, devido aos constantes relatos de resistência. A obtenção

\footnotetext{
${ }^{1}$ Recebido em 26 de julho de 2013.

Aceito para publicação em 28 de outubro de 2013.

${ }^{2}$ Laboratório de Doenças Parasitárias, Universidade Federal do Paraná (UFPR), Rua dos Funcionários 1540, Curitiba, PR 80035-050, Brasil. E-mail: molento@ufpr.br*Autor para correspondência: fortesfs@gmail.com
}

de um diagnóstico preciso e precoce da resistência é extremamente importante para auxiliar a tomada de decisão em programas de controle parasitário, com o objetivo de preservar a vida útil dos produtos e limitar o desenvolvimento da resistência nas populações de nematoides. Os testes in vivo e, mais recentemente, os testes in vitro têm sido desenvolvidos para a detecção de nematoides resistentes aos principais grupos de anti-helmínticos. No entanto, a disponibilidade de testes in vitro validados e o seu uso prático ainda são muito limitados. Embora o teste de redução na contagem de ovos nas fezes (TRCOF, in vivo - indireto) seja o principal método de escolha para a detecção de resistência no campo, vem recebendo críticas quanto à validade dos resultados, e passa por significativas modificações. Além disso, o desenvolvimento de técnicas moleculares a partir 
de alterações genômicas gerou avanços consideráveis nessa área de investigação, com o uso de mutações nos códons 167,198 e 200 do gene da $\beta$-tubulina como principais SNPs (polimorfismos de nucleotídeo único; do inglês Single $\mathrm{Nu}$ cleotide Polymorphisms) associados à resistência aos BZs. A presente revisão tem o objetivo de discutir os métodos de diagnóstico disponíveis para a detecção de resistência anti-helmíntica em nematoides de pequenos ruminantes, destacando progressos e obstáculos para seu uso na rotina laboratorial e no campo.

TERMOS DE INDEXAÇÃO: Anti-helmínticos, resistência anti-helmíntica, nematoides gastrintestinais, Haemonchus contortus, ovinos, testes in vivo, testes in vitro, eficácia.

\section{INTRODUÇÃO}

A alta prevalência de infecções parasitárias e a dificuldade de realizar um controle efetivo de nematoides gastrintestinais em criações de pequenos ruminantes têm grande importância devido aos prejuízos causados ao desempenho zootécnico e ao bem-estar animal. Nas últimas décadas, o uso intensivo de anti-helmínticos pertencentes aos grupos dos benzimidazóis (BZs), dos imidazotiazóis (levamisole, LEV) e das lactonas macrocíclicas (avermectinas e milbemicinas, LMs) demonstrou um impacto positivo inicial durante uma década, mas atualmente constitui a forma mais desastrosa de controle, resultando na seleção e propagação de parasitos resistentes com alto índice de homozigose (RR) e perda total da heterogenia para indivíduos suscetíveis (SS). Esse é um tema de preocupação mundial crescente, e representa uma ameaça ao controle parasitário de médio e longo prazo, tendo em vista a precária melhoria na condição dos animais, mesmo após o tratamento. 0 controle químico continua a ser preocupante, pois é praticado com medicamentos contendo alta concentração ou mesmo com o uso da combinação de medicamentos, muitas vezes sem critério de produção e/ou indicação para sua ampla utilização. Recentemente, duas novas classes de anti-helmínticos - monepantel (Kaminsky et al. 2008) e derquantel, este em combinação com a abamectina (Little et al. 2010) -, com novos modos de ação, foram lançados no mercado na Nova Zelândia, sendo uma alternativa promissora para o futuro do controle de nematoides gastrintestinais.

Embora seja crescente o desenvolvimento e a adoção de programas alternativos de controle parasitário (Molento et al. 2011), visando à redução da aplicação de compostos químicos, as atuais medidas de controle ainda dependem fortemente do uso de anti-helmínticos. Sabe-se que o processo de seleção de parasitos resistentes após sua exposição aos produtos químicos é inevitável e, além disso, o desenvolvimento/comercialização de novas drogas é lento e excessivamente caro (Geary 2013). Assim, é de extrema importância prolongar a vida útil dos produtos existentes - antigos e novos - por meio de sua utilização estratégica/ seletiva, a fim de manter o adequado controle do parasitismo.

Os relatos de resistência anti-helmíntica em nematoides de pequenos ruminantes para os três grupos de drogas mais comumente utilizados, BZs, LEV e LMs, têm crescido rapidamente em diferentes regiões do mundo, incluindo América do Sul (Molento et al. 2011, Torres-Acosta et al. 2012), África do Sul (Van Wyk et al. 1999), Austrália (Love \& Coles 2002), Nova Zelândia (McKenna 2010) e Europa (Papadopoulos et al. 2012), representando uma séria ameaça à produção animal. No Brasil, o aumento de relatos de resistência mútipla a drogas (RMD) em vários locais, como as regiões Sul (Cezar et al. 2010), Sudeste (Veríssimo et al. 2010) e Centro-Oeste (Sczesny-Moraes et al. 2010), evidenciam a gravidade desse problema. Conforme verificado em testes de eficácia a campo, $100 \%$ das propriedades já apresentam RMD (Veríssimo et al. 2010).

Buscando retardar o avanço da resistência, o uso de testes sensíveis para determinar o grau de eficácia de uma determinada droga, em uma população específica de parasitos, pode auxiliar o planejamento de estratégias de controle (Taylor et al. 2002), como a simples opção de uso de compostos que ainda permaneçam eficazes. Contudo, mesmo sendo de fundamental importância, o diagnóstico da resistência anti-helmíntica, ou da redução de eficácia aos anti-helmínticos, ainda não é uma realidade prática no campo (Torres-Acosta et al. 2012). Muito embora a resistência possa ser avaliada por meio de testes in vivo e in vitro, a disponibilidade de testes in vitro validados para o diagnóstico da resistência ainda é muito limitada, com poucos laboratórios que oferecem esse tipo de serviço. Tais testes ainda apresentam limitações quanto à sua confecção e ao alto nível de treinamento técnico para a interpretação dos achados. Quanto ao teste in vivo controlado, é inviável para a condição de avaliação a campo, devido à necessidade de sacrifício dos animais e ao alto custo. Consequentemente, o teste fenotípico indireto in vivo de redução na contagem de ovos nas fezes (TRCOF) continua sendo o principal método de escolha para a detecção de resistência (Kaplan \& Vidyashankar 2012), sendo amplamente aceito por agências reguladoras e pela própria indústria farmacêutica, bem como para publicações científicas. Vários laboratórios estão trabalhando arduamente para obter o diagnóstico molecular da resistência (Samson-Himmelstjerna et al. 2009b), mas o mecanismo resultante dos rearranjos genéticos ainda é considerado um quebra-cabeças.

A variação em protocolos experimentais para a execução dos testes de diagnóstico da resistência, os métodos de análise e a interpretação dos dados, podem gerar resultados de qualidade muito variável. Assim, o desenvolvimento de novos métodos e a padronização e validação dos já existentes são essenciais para permitir a comparação de dados obtidos em diferentes laboratórios, além de sua inclusão na rotina laboratorial (Chagas et al. 2011, Molento et al. 2012).

Esta revisão tem o objetivo de discutir os principais testes atualmente disponíveis - in vivo, in vitro e moleculares - para o diagnóstico da resistência anti-helmíntica em nematoides gastrintestinais de pequenos ruminantes, os avanços proporcionados por novas tecnologias e as limitações para o seu uso na rotina laboratorial e no campo. 


\section{MÉTODOS PARA DETECÇÃO DE RESISTÊNCIA ANTI-HELMÍNTICA EM NEMATOIDES GASTRINTESTINAIS DE PEQUENOS RUMINANTES}

Desde a recomendação de testes para detecção de resistência anti-helmíntica pela Associação Mundial para o Avanço da Parasitologia Veterinária (World Association for the Advancement of Veterinary Parasitology - WAAVP) (Coles et al. 1992) e sua revisão e inclusão de métodos para discussão e avaliação (Coles et al. 2006), uma variedade de métodos in vivo e in vitro para o diagnóstico da resistência em muitas espécies de nematoides foi descrita, nas últimas décadas. Técnicas moleculares também têm sido desenvolvidas, porém apenas para poucas espécies de parasitos. Assim, é indispensável a identificação correta das espécies de parasitos presentes no hospedeiro para a obtenção de um diagnóstico apropriado, particularmente quando há comparação entre amostras pré e pós-tratamento (Demeler et al. 2012b). Descrições detalhadas e orientações sobre o uso das principais técnicas disponíveis estão presentes em trabalhos anteriores (Coles et al. 1992, Taylor et al. 2002, Coles et al., 2006), possibilitando a execução e a avaliação dos testes internacionalmente. Todos os métodos possuem, em algum grau, limitações em termos de confiabilidade, reprodutibilidade, sensibilidade, aplicabilidade, interpretação ou custo (Taylor et al. 2002). Além disso, não abrangem de maneira satisfatória todos os grupos de anti-helmínticos.

0 TRCOF in vivo é o método mais amplamente utilizado para a detecção e o monitoramento da resistência anti-helmíntica. No entanto, é considerado o menos sensível e pouco confiável para a detecção da resistência. Trata-se de um teste simples, de execução relativamente fácil e que pode ser usado com todos os grupos de anti-helmínticos, independentemente do seu mecanismo de ação. A eficácia da droga é estimada por meio da comparação das contagens de ovos de nematoides nas fezes antes e depois do tratamento, sendo o tempo definido de acordo com o grupo testado. A população de parasitos é considerada resistente quando a redução é < 95\%. Em comparação com o TRCOF, o teste controlado de eficácia, outro método in vivo, avalia melhor a realidade da infecção e o efeito do composto. Nesse teste, animais natural ou experimentalmente infectados são separados em grupos (tratamento(s) e controle) e a dose do anti-helmíntico utilizado deverá ser a dose terapêutica recomendada pelo fabricante, cuja eficácia esperada é $\geq 99 \%$. Após a necropsia dos animais, realiza-se a contagem dos parasitos presentes no hospedeiro. Então, observa-se a redução ou a eliminação dos parasitos, e estima-se a eficácia do tratamento. Da mesma forma, se a eficácia for $<95 \%$, confirma-se a presença de resistência anti-helmíntica. Quando há uma baixa prevalência de nematoides resistentes, estes podem não ser detectados devido a pequenos aumentos na dose, que podem causar a morte de $95 \%$ dos vermes. Assim, como a dose registada é frequentemente maior do que a real dose efetiva necessária para a remoção dos vermes, algum ajuste deve ser feito para a realização do teste controlado (Coles et al. 2006). Devido ao pouco uso desse teste, o mesmo não será abordado em detalhes no presente artigo.
Como alternativa aos métodos in vivo, um crescente número de testes in vitro para a detecção de resistência anti-helmíntica vem sendo desenvolvido e adaptado para diferentes grupos de drogas. Eles são, na maioria das vezes, mais rápidos, mais econômicos e menos trabalhosos do que os in vivo (Demeler et al. 2012a). Os métodos in vitro ainda anulam os efeitos causados pela interferência do hospedeiro no estabelecimento da infecção parasitária e pela variação na farmacodinâmica das drogas no animal (Chagas et al. 2011). No entanto, há poucos relatos de testes in vitro padronizados até o momento. Em geral, esses testes baseiam-se na incubação de estágios de vida livre do parasito em uma série de concentrações do anti-helmíntico, seguido da avaliação de seus efeitos sobre os nematoides. São geradas curvas de dose-resposta e valores de $\mathrm{DL}_{50}$ (dose do anti-helmíntico necessária para matar 50\% dos parasitos) ou $\mathrm{DL}_{95}$ (dose do anti-helmíntico necessária para matar 95\% dos parasitos). A Fig. 1 exemplifica a obtenção de curvas de dose-resposta para um isolado de $\mathrm{Ha}$ emonchus contortus testado para duas drogas (ivermectina - IVM e moxidectina - MOX), mostrando um valor de $\mathrm{DL}_{50}$ para MOX significativamente menor do que para IVM. Atualmente, os principais testes disponíveis avaliam: a eclosão (teste da eclodibilidade de ovos - TEO); o desenvolvimento (teste de desenvolvimento larvar - TDL); a motilidade/ migração (teste de motilidade larvar e teste de inibição da migração larvar); e a alimentação (teste de inibição da alimentação larvar) (Demeler et al. 2012b). Desses, o TEO e o TDL são os mais comumente utilizados. Apenas o TDL possui um teste comercial (DrenchRite ${ }^{\circledR}$ ), disponível em alguns países e de custo elevado. 0 uso dos outros testes in vitro tem sido limitado principalmente à área de pesquisa científica, utilizando isolados de parasitos cujo estado de resistência ou suscetibilidade foi previamente determinado. O TEO consiste na incubação de ovos não desenvolvidos

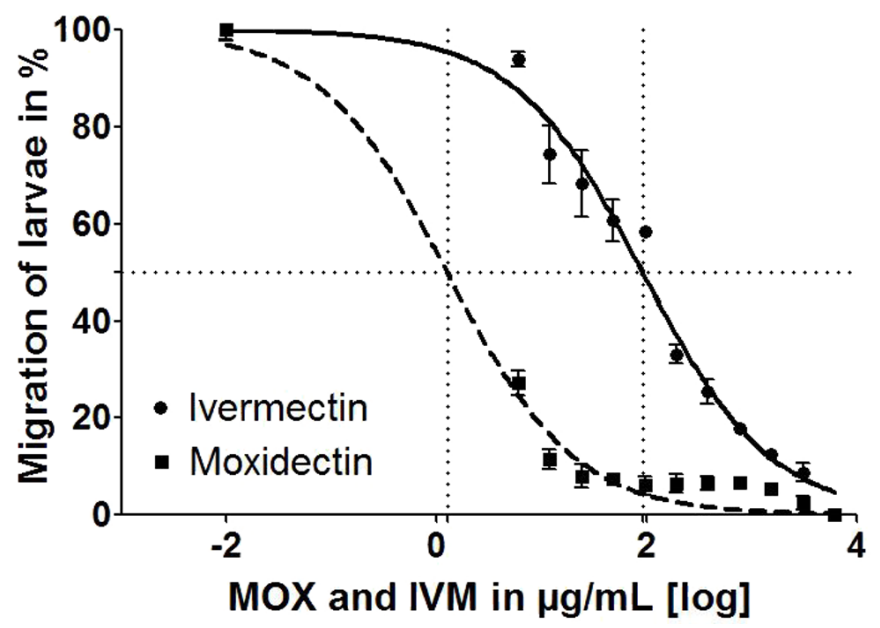

Fig.1. Curvas de dose-resposta obtidas com o Teste de Migração de Larvas em Ágar com o isolado SP15030vi2011 de Haemonchus contortus usando ivermectina (IVM, linha sólida) e moxidectina (MOX, linha tracejada). As barras de erro indicam o erro padrão. As barras de erro não são vistas quando as diferenças entre os valores observados para todas as concentrações testadas foram iguais ou muito próximas de 0 (zero) (Fortes et al. 2013). 
em concentrações crescentes do anti-helmíntico, e pode ser usado com sucesso para a detecção de resistência aos BZs (Samson-Himmelstjerna et al. 2009a), cuja ação impede o embrionamento e a eclosão de ovos de nematoides. Para outras drogas anti-helmínticas sem nenhuma atividade ovicida, como LMs ou LEV, ainda faltam testes in vitro altamente satisfatórios para a detecção de resistência. Uma dose discriminante - dose que impede a eclosão de 99\% dos ovos suscetíveis - também pode ser usada, ao invéz de $\mathrm{DL}_{50}$, sendo estimada a porcentagem de ovos resistentes em amostras de fezes, aumentando a sensibilidade do ensaio (Coles et al. 2006). Já o TDL baseia-se no desenvolvimento de ovos de parasitos em larvas de terceiro estágio $\left(\mathrm{L}_{3}\right)$. Uma série de versões do TDL já foi desenvolvida para a detecção de resistência a todas as classes de anti-helmínticos, usando soluções líquidas ou ágar como base para o teste. A dose discriminante também pode aumentar a sensibilidade e simplicidade do teste.

Nos últimos anos, métodos de diagnóstico molecular da resistência anti-helmíntica a partir de alterações genômicas têm sido desenvolvidos, trazendo avanços consideráveis nessa área de investigação. Em geral, os testes moleculares possuem maior sensibilidade e especificidade e podem fornecer ferramentas poderosas para superar muitas das desvantagens dos métodos acima referidos, mas requerem pesquisas adicionais para serem usados como uma ferramenta universal prática no campo. A sensibilidade - capacidade de detectar os indivíduos verdadeiramente positivos, ou seja, diagnosticar corretamente os doentes - e a especificidade - capacidade de detectar os indivíduos verdadeiramente negativos, ou seja, diagnosticar corretamente os sadios - são importantes indicadores para a avaliação de um teste diagnóstico. É considerado o melhor teste aquele que apresenta alta sensibilidade e alta especificidade, fornecendo poucos resultados falso-positivos e falso-negativos, que pode ser obtido com o aprimoramento das técnicas moleculares e dos métodos de análise padrão.

Vários estudos vêm sendo feitos buscando a determinação de marcadores genéticos para a resistência anti-helmíntica, incluindo a identificação de polimorfismos de nucleotídeo único (SNPs, do inglês Single Nucleotide Polymorphisms) para avaliar frequências alélicas em populações (Samson-Himmelsjerna 2006). Até o momento, testes moleculares estão disponíveis apenas para o grupo dos BZs, em algumas espécies de nematoides de ovinos. Metodologias utilizando a reação em cadeia pela polimerase (PCR) têm sido estabelecidas para a avaliação da presença, ausência ou quantificação de SNPs associados à resistência aos BZs no isotipo 1 do gene da $\beta$-tubulina, alvo dessas drogas. A elucidação insuficiente sobre os mecanismos moleculares envolvidos na resistência ao LEV e às LMs em nematoides, drogas de resistência poligênica, torna mais complexo e desafiador o desenvolvimento de marcadores moleculares para o diagnóstico da resistência a esses compostos. Estudos baseados em diagnóstico imunológico utilizando ELISA para a detecção de antígeno em parasitos também já foram sugeridos. Recentemente, foram detectadas diferenças de expressão de proteína entre isolados de Haemonchus contortus resistente e suscetível à IVM por meio de análises de proteômica de fingerprinting (Hart et al. 2012), sugerindo ser uma possível base para fenotipagem molecular ou marcadores de resistência.

\section{Técnicas in vivo}

Teste de Redução na Contagem de Ovos nas Fezes (TRCOF). O TRCOF, segundo recomendações da WAAVP (Coles et al. 1992), é considerado o método de escolha para o monitoramento da eficácia anti-helmíntica devido à sua fácil execução e interpretação, sendo realizado com uma sequência de exames de contagem de ovos por grama de fezes (OPG). Quanto à OPG, trata-se de um teste fenotípico cuja contagem depende diretamente do efeito do hospedeiro, e é considerado indireto, pois reflete a postura de ovos das fêmeas, que depende do efeito da resposta imune do hospedeiro. Entretanto, sua execução e/ou interpretação tem sido dificultada por um conjunto de fatores que serão detalhados a seguir. O TRCOF é considerado confiável somente quando há mais de $25 \%$ de vermes resistentes em uma população (Martin et al. 1989), e dados obtidos mais recentemente não mostraram uma alta reprodutibilidade do teste (Miller et al. 2006). Assim, o valor diagnóstico do teste para situações de emergência e baixa prevalência da resistência é limitado. A pouca importância dada à interação hospedeiro-parasito de acordo com cada espécie animal e parasitária, a viabilidade do teste em condições de campo e as indicações de concentração para a contagem de ovos são outros fatores limitadores importantes (Levecke et al. 2012).

As recomendações referentes ao delineamento do estudo e à dimensão da amostra podem ser de difícil obtenção no campo. Assim, buscando garantir resultados favoráveis com o TRCOF, Levecke et al. (2012) desenvolveram um método que permite aos pesquisadores adaptarem seu projeto de estudo conforme uma ampla gama de condições de campo. A inclusão de um grupo não tratado (controle) no teste, para observação de alterações naturais que possam ocorrer na contagem de ovos durante o período, pode não ser prática em muitas situações. Além disso, o uso de médias aritméticas das contagens de ovos nas fezes dos mesmos animais antes e após a administração do anti-helmíntico, ao invés de aleatoriamente, pode proporcionar resultados mais confiáveis (Dobson et al. 2012).

A avaliação do teste pode ser prejudicada devido às variações na correlação entre a contagem de ovos nas fezes e a carga parasitária adulta entre as diferentes espécies de parasitos. Foi encontrada uma boa correlação para H. contortus (Roberts \& Swan 1981, Chagas et al. 2013), porém não para T. colubriformis (Sangster et al. 1979), Ostertagia circumcincta (Martin et al. 1985) e Nematodirus spp. (Martin et al. 1985). Palcy et al. (2010) relataram uma baixa sensibilidade do teste para a detecção de T. axei, cuja postura de ovos é muito baixa. Assim, a ocorrência de variação intra e interespécies na fecundidade e agregação dos ovos nas fezes pode afetar a interpretação do TRCOF (Levecke et al. 2012).

Algumas drogas podem causar uma supressão temporária na postura de ovos, levando a uma superestimativa da eficácia anti-helmíntica se avaliada durante esse período. Portanto, recomenda-se que amostras fecais sejam co- 
letadas 3-7 dias após o uso de LEV, 8-10 dias para BZs e entre 14-17 dias para LMs. Somente quando for utilizada moxidectina (MOX), uma LM, as fezes deverão ser coletadas após 21 dias. Quando mais de um tipo de droga estiver sendo avaliado, o período de 14 dias deverá ser empregado (Coles et al. 2006). Após o tratamento anti-helmíntico, deve-se ter atenção com os locais onde os animais serão mantidos, se pasto ou piquete, devido à possibilidade de rápida reinfecção. Uma redução superior a 95\% no TRCOF indica que o uso do anti-helmíntico ainda deve ser benéfico em programas de controle parasitário, mas uma pequena porcentagem de vermes sobreviventes pode indicar um problema de resistência, que pode aumentar com tratamentos subsequentes, e precisa ser monitorado.

A precisão do TRCOF depende da sensibilidade da técnica adotada para a contagem de ovos de nematoides nas fezes, sendo que a maioria dos métodos atualmente disponíveis ainda não é precisa (Demeler et al. 2012b). 0 uso da técnica descrita por Gordon \& Whitlock modificada (câmara McMaster com detecção de 50 OPG) pode não detectar um baixo número de ovos, dificultando o diagnóstico de resistência precoce e de pequenas alterações na eficácia de uma droga (Kaplan \& Vidyashankar 2012). Assim, acredita-se que é necessária a adoção de um novo método para contagem, que ofereça maior sensibilidade e precisão (Demeler et al. 2012b). Diferentes reduções percentuais na contagem de ovos podem ser obtidas, dependendo do tipo de contagem, devendo-se adotar um padrão dos métodos de cálculo. Porém, como existem muitas variações na técnica de OPG, sua padronização é dificultada (Coles et al. 1992). Alguns laboratórios utilizam pool de amostras de fezes e outros realizam contagens individuais para a obtenção de um valor médio. Ambas as abordagens têm vantagens e desvantagens, e a definição do melhor procedimento para a contagem de ovos nas fezes é importante. Por exemplo, enquanto o teste de OPG - desenvolvido para contagem de ovos em ovinos - pode ser a melhor opção para amostras individuas de ovinos, o teste FECPAK ${ }^{\circledR}$ pode ser melhor para um pool de amostras (Coles et al. 2006). Já a lâmina FLOTAC $^{\circledR}$ é usada em uma técnica recentemente descrita que também apresentou uma melhora significativa com relação à sensibilidade (Rinaldi et al. 2011, Molento et al. 2012). Estudos recentes vêm sendo feitos com um sistema mini-FLOTAC, mostrando uma diminuição significativa na média e no desvio padrão de valores em comparação com a técnica de Gordon \& Whitlock (Molento et al. 2012). As diferenças na fecundidade entre as espécies de helmintos também demandam diferentes métodos de contagem (Levecke et al. 2012). Outro aspecto relevante é que apesar de a OPG ser altamente variável, ela geralmente é feita a partir de uma única contagem por animal pré e pós-tratamento, ao invés de triplicatas para reduzir a variabilidade (Kaplan \& Vidyashankar 2012).

Em geral, as populações de nematoides compreendem várias espécies, sendo essencial identificar quais estão envolvidas e, assim, avaliar o efeito de uma droga em diferentes espécies nas populações. Como os ovos nas fezes não podem ser diferenciados morfologicamente (exceto o Nematodirus), recomenda-se que coproculturas de amos- tras pré e pós-tratamento sejam conduzidas separadamente para o desenvolvimento dos ovos até $\mathrm{L}_{3}$ (Roberts \& O'Sullivan 1950). A identificação das larvas geralmente é feita utilizando-se um guia simplificado para consulta (Ueno \& Gonçalves 1998), mas é necessária experiência técnica devido à dificuldade e pouca confiabilidade associada ao método. Além disso, as necessidades para incubação e desenvolvimento das larvas diferem entre as espécies de nematoides, e as condições das coproculturas podem favorecer o desenvolvimento de uma espécie e prejudicar o de outra. Por isso, as condições devem ser as mesmas para coproculturas pré e pós-tratamento. Recomenda-se que as amostras não devem ser mantidas a $4^{\stackrel{0}{ } \mathrm{C}}$ por período acima de 24 horas, para que não haja interferência na incubação dos ovos de $H$. contortus e Cooperia (McKenna 1998). Recentemente, Roeber et al. (2012) sugeriram um ensaio de PCR previamente avaliado (98\% de sensibilidade e 100\% de especificidade) para ser usado como alternativa à técnica de coprocultura, sendo que o primeiro foi considerado menos trabalhoso e mais rápido.

Na prática, outros fatores ainda podem prejudicar a interpretação dos dados obtidos com o TRCOF e reduzir a especificidade do teste, como as diferenças metodológicas entre os laboratórios, a incorreta administração de medicamentos, falhas de equipamentos, erro nas doses de drogas e produtos de má qualidade. Para aperfeiçoar o TRCOF, estudos vêm sendo feitos com base em comparações de métodos de contagem de ovos nas fezes (Rinaldi et al. 2011), programas estatísticos (Dobson et al. 2012), além de outras questões como o período para a realização de amostragens e a manipulação e conservação das amostras. Há ainda questionamentos sobre o grau de sensibilidade do TRCOF, e sobre como os resultados podem ser relacionados com os dados obtidos a partir de testes in vitro (Coles et al. 2006), a fim de aprimorar o seu uso.

\section{Técnicas in vitro}

Teste de eclodibilidade de ovos (TEO). 0 método foi descrito, inicialmente, por Le Jambre (1979), e um protocolo padronizado foi adotado pela WAAVP (Coles et al. 1992). 0 TEO tem sido utilizado com várias modificações por uma série de pesquisadores, para a detecção de resistência a BZs e LEV. Um protocolo-padrão para a detecção de resistência aos BZs está disponível (Samson-Himmelstjerna et al. 2009a), e laboratórios de toda a Europa utilizam a mesma metodologia. A maioria dos estudos que avaliaram o uso do TEO para a detecção de nematoides resistentes aos BZs mostrou uma boa concordância com os resultados obtidos com o TRCOF em ovinos (Várady et al. 2006, Díez-Baños et al. 2008) e bovinos (Demeler et al. 2012a). Isso indica que o teste representa uma alternativa confiável e precisa para o TRCOF, além de ser mais prático e economicamente viável.

0 tiabendazol (TBZ) é a droga de escolha para a realização do teste por possuir uma solubilidade relativamente elevada em água. Sua estabilidade a longo prazo em soluções de DMSO não é conhecida, mas quando as diluições são feitas em água pode haver uma redução das concentrações esperadas. Como a sensibilidade ao TBZ diminui na medida em que os ovos se desenvolvem, as fezes destinadas ao 
exame devem ser manipuladas até três horas após a coleta ou armazenadas anaerobicamente (Coles et al. 2006). Isso, muitas vezes, representa uma grande limitação ao uso do TEO no diagnóstico de rotina.

Porcentagens de ovos eclodidos para cada concentração do fármaco, curvas de dose-resposta e valores de $\mathrm{DL}_{50}$ podem ser determinadas com essa técnica. Utilizando-se uma dose discriminante, pode-se obter a porcentagem de ovos eclodidos (resistentes ao BZs) na amostra. Dados obtidos com isolados suscetíveis de $H$. contortus, $T$. circumcincta e Trichostrongylus colubriformis mostraram uma dose discriminante de $0,1 \mu \mathrm{g} / \mathrm{ml}$ de TBZ. Testes de campo também já demonstraram que ovos de outras espécies sensíveis (Cooperia e Oesophagostomum) não eclodem com essa concentração. Usando esse critério, acredita-se que possam ser detectados apenas 2 a 3\% de ovos resistentes (Coles et al. 2006). Na Espanha, a dose discriminante única foi utilizada para avaliar o estado de resistência aos BZs no nordeste do país, aumentando a sensibilidade do TEO (Calvete et al. 2011).

Alguns fatores em investigação e que podem influenciar os resultados obtidos com o TEO, incluem: diferentes fontes de água utilizada (destilada, desionizada ou água da torneira); grau de limpeza dos ovos (presença de detritos); e o método de dissolução da amostra (p.ex. DMSO e água) (Coles et al. 2006). Como os ovos são muito frágeis e sensíveis à variação de temperatura, a detecção de tais fatores é essencial para que diferentes laboratórios possam obter resultados igualmente eficazes.

Teste de desenvolvimento larvar (TDL). 0 TDL foi relatado primeiramente por Coles et al. (1988) para a detecção de resistência a BZs e LEV. Muitas variações do teste foram publicadas descrevendo seu uso para a detecção de resistência de várias drogas anti-helmínticas em nematoides de ovinos (Hubert \& Kerboeuf 1992, Gill et al. 1995). Um teste comercial $\left(\right.$ DrenchRite $^{\circledR}$ ) foi desenvolvido na Austrália para determinar a resistência contra BZs, LEV e LMs em nematoides de ovinos e caprinos, porém é pouco utilizado e expressivamente caro para o uso em rotina. 0 TDL em microágar (do inglês MALDT, micro-agar larval development test) foi descrito em detalhes (Coles et al. 2006) e, assim como o TEO, foram encontrados resultados em boa concordância com dados obtidos após a realização do TRCOF (Leathwick et al. 2006, Várady et al. 2006). O teste tem demonstrado ser confiável para BZs e LEV (Taylor et al. 2002, Coles et al. 2006) e, recentemente, foram relatados resultados comparáveis e confiáveis para detectar a resistência à IVM em H. contortus (Dolinská et al. 2012).

Utilizando o MALDT descrito por Coles et al. (2006), Dolinská et al. (2012) distinguiram facilmente isolados de H. contortus suscetíveis e resistentes à IVM, obtendo uma probabilidade aproximada de $87 \%$ para o diagnóstico positivo em uma população com apenas $2-4 \%$ de vermes resistentes. Nesse estudo, dois fatores foram indicados por contribuir para a falta de sensibilidade do teste: a forma de apresentação da IVM e seus análogos, pois esses podem ter diferentes potências contra diferentes espécies de nematoides gastrintestinais; e a correlação entre dados obtidos em testes in vitro MALDT e in vivo TRCOF, sabendo que o último pode apresentar resultado questionável.
A dose letal de 50\% $\left(\mathrm{DL}_{50}\right)$ determinada para nematoides suscetíveis de ovinos foi de $0,02 \mu \mathrm{g} / \mathrm{ml}$ para TBZ e $0,5 \mu \mathrm{g} / \mathrm{ml}$ para LEV. Contudo, pesquisas adicionais são necessárias para confirmar esses valores no TDL (Coles et al. 2006). Essa prova é considerada relativamente frágil, pois requer fezes frescas (enviadas ao laboratório em sistema anaeróbio), sendo as condições de armazenamento as que mais afetam o desenvolvimento dos ovos e o bom desempenho do teste (Demeler et al. 2010). Ao contrário do TEO, para o TDL a idade dos ovos utilizados não importa, e as larvas são obtidas para a diferenciação de espécies. A principal vantagem do TDL é a sua capacidade de avaliação simultânea de resistência a várias drogas (BZs, LEV e LMs), em uma mesma placa.

Para os testes in vitro, grandes quantidades de dados precisam ser coletadas para definir um Procedimento Operacional Padrão (POP) com as possíveis interpretações. É preciso ainda determinar a relação entre esses testes padronizados e o TRCOF. Embora o TDL funcione para o diagnóstico de resistência aos BZs, parece não ser tão satisfatório quanto o TEO (Coles et al. 2006).

Testes de motilidade e migração larvar. Os testes de motilidade e migração larvar podem ser usados para avaliar o efeito dos anti-helmínticos que causam paralisia na musculatura somática dos parasitos. A motilidade de larvas pode ser determinada por meio de observação, detectores eletrônicos (instrumentos que medem o grau de refração da luz e fornecem um índice de motilidade) ou migração através de peneiras. A grande necessidade de se obter um diagnóstico confiável para a resistência às LMs tem estimulado o desenvolvimento de testes que avaliam a motilidade dos parasitos utilizando essas técnicas.

Testes mensurando a paralisia larval foram desenvolvidos para a detecção de resistência ao LEV e ao morantel (Martin \& LeJambre 1979). Sutherland \& Lee (1990) descreveram uma modificação desse teste para a detecção de resistência ao TBZ. Gill et al. (1991) relataram um teste de migração para a detecção de resistência à IVM em $H$. contortus e, mais tarde, em Trichostrongylus colubriformis e T. circumcincta (Gill \& Lacey 1998), mas a avaliação da motilidade das larvas foi muito subjetiva. Assim, foi feita a avaliação e validação do uso de ágar e de peneiras para a separação de $\mathrm{L}_{3}$ migrantes (sobreviventes) e não migrantes (mortas) para uma quantificação confiável (D'assonville et al. 1996, Kotze et al. 2006). Além desses, uma grande variedade de testes semelhantes de migração de larvas foi publicada, sendo adaptadas para o uso de diferentes drogas e espécies de nematoides de ovinos (Wagland et al. 1992, Douch \& Morum 1994, Molento \& Prichard 2001). No entanto, em nenhum desses trabalhos houve a publicação de dados referentes à repetibilidade de resultados obtidos dentro de um mesmo laboratório e/ou à reprodutibilidade de resultados entre laboratórios distintos. Isto se faz necessário, pois pode significar um melhor monitoramento da eficácia das LMs, entre outras drogas, em menor tempo e sem o uso de animais experimentais como, por exemplo, no teste controlado.

Um teste de inibição da migração larvar (TIML) para a detecção de resistência à IVM em nematoides de rumi- 
nantes foi padronizado na Europa (Demeler et al. 2010), permitindo a separação das larvas móveis das imóveis por meio da migração através das peneiras. 0 mesmo protocolo foi realizado em seis laboratórios de cinco países, mostrando resultados altamente reprodutíveis, e fornecendo uma ferramenta útil para o monitoramento da resistência à IVM em nematoides de ruminantes.

A aplicabilidade do teste no campo, onde infecções mistas de parasitos ocorrem comumente, ainda precisa ser mais bem estudada, sendo necessários estudos que possibilitem a diferenciação das espécies (Kotze et al. 2006). Um estudo mostrou uma boa concordância dos resultados obtidos a partir do TIML com o TRCOF em bovinos (Demeler et al. 2012a), demonstrando o potencial uso do TIML. 0 método também foi utilizado para avaliar a eficácia in vitro de IVM e MOX em isolados de Cooperia sp. (Almeida et al. 2013) e em isolado de $H$. contortus (Fortes et al. 2013), mostrando ser um teste possivelmente útil para a avaliação de eficácia da IVM. Em comparação ao TDL, o TIML é um exame fácil e simples, possível de ser realizado na maioria dos laboratórios. Além disso, o TIML requer larvas de terceiro estágio, que podem ser facilmente obtidas a partir de coproculturas, e mantidas em geladeira até o seu uso (Demeler et al. 2010).

A motilidade de larvas e adultos de nematoides, após incubação com anti-helmínticos, também pode ser estimada por meio de um instrumento que mede o grau de refração da luz e fornece um índice de motilidade. 0 movimento dos parasitos causa uma variação dos sinais luminosos refletidos e recebidos pelo fotodetector. Os efeitos anti-helmínticos in vitro sobre $H$. contortus resistentes aos BZs foram detectados utilizando esse medidor de micromotilidade (Folz et al. 1987). Recentemente, um medidor de micromotilidade também foi utilizado com eficiência para avaliar a ação de IVM sobre parasitos adultos de $C$. oncophora (Demeler et al. 2010).

Testes de alimentação. Estudos têm sido realizados para determinar o efeito sobre a alimentação do parasito após tratamento anti-helmíntico em larvas e adultos. 0 teste de inibição da alimentação larvar (TIAL) foi usado para diferenciar isolados monoespecíficos de nematoides resistentes e suscetíveis à IVM (Alvarez-Sánches et al. 2005) e isolados de campo resistentes e suscetíveis, compostos principalmente por Teladorsagia circumcincta (Martínez-Valladares et al. 2012). Em um estudo realizado no noroeste da Espanha, os valores de resistência ao LEV e às LMs encontrados com o TIAL foram semelhantes aos obtidos pelo TRCOF, porém foram feitos em diferentes rebanhos (Martínez-Valladares et al. 2013). Díez-Baños et al. (2008) avaliaram a eficácia anti-helmíntica no campo e encontraram um valor mais elevado de resistência às LMs utilizando o TIAL (10\%), comparado ao TRCOF (3\%). Isso indica que o teste in vitro tem o potencial de detectar a resistência à classe de drogas mais comumente utilizada.

\section{TÉCNICAS MOLECULARES PARA 0 DIAGNÓSTICO DA RESISTÊNCIA}

Muito se tem investido para o desenvolvimento de um método diagnóstico de parasitos resistentes utilizando técnicas moleculares. Entretanto, devido ao carácter extremamente poligênico das populações, pesquisadores continuam sendo desafiados a descobrir o mecanismo de resistência das drogas e divulgar um ou mais candidatos a marcador específico. 0 principal mecanismo molecular associado à resistência aos BZs em nematoides tricostrongilídeos de pequenos ruminantes envolve uma mutação transversão $\mathrm{T}>\mathrm{A}$, modificando o códon TTC para TAC - que leva à substituição do aminoácido fenilalanina por tirosina na posição 200 (polimorfismo Phe200Tyr) no isotipo 1 do gene da $\beta$-tubulina, em isolados resistentes de $H$. contortus, T. colubriformis e O. circumcincta (Kwa et al. 1994, 1995, Elard et al. 1996, 1999, Silvestre \& Humbert 2000). Tal polimorfismo também tem sido associado à resistência às LMs (Mottier \& Prichard 2008). Já foram descritas outras mutações, menos frequentes: no códon 167 (Phe167Tyr) em H. contortus e T. circumcincta (Silvestre \& Cabaret 2002), modificando também o códon TTC para TAC; e no códon 198 (Glu200Ala), que codifica alanina em vez de glutamato em isolados resistentes, em $H$. contortus resistente a BZs (Ghisi et al. 2007, Rufener et al. 2009a), alterando o códon GAA para GCA. Essas mutações nos códons 167, 198 e 200 podem, então, ser utilizadas como marcadores para a detecção de resistência aos BZs nesses parasitos, sendo importante conhecer os efeitos da associação entre os SNPs e o nível de homozigoze/heterozigose presente (Silvestre \& Cabaret 2002, Barrère et al. 2012). Barrère et al. (2012) indicam que os testes de resistência para BZs no campo deveriam avaliar a heterozigose dos SNPs 167 e 200 para obter melhores resultados. Protocolos de PCR convencional e em tempo real (rt-PCR) foram analisados para a detecção de SNPs nos códons 167 e 200 na $\beta$-tubulina (Samson-Himmelstjerna 2006). Para a determinação da resistência associada ao códon TAC na posição 200, técnicas de PCR-RFLP (restriction fragment length polymorphism ou polimorfismo de comprimento de fragmentos de restrição) foram desenvolvidas para $H$. contortus (Tiwari et al. 2006) e T. circumcincta (Shayan et al. 2007). A técnica de pirosequenciamento também se mostrou rápida e adequada para a detecção múltipla de SNPs (Samson-Himmelstjerna et al. 2007). A quantificação dos alelos de resistência/suscetibilidade no DNA extraído de pool de larvas de nematoides pode ser feita usando as técnicas de PCR em tempo real e pirosequenciamento, permitindo uma avaliação sensível, confiável e economicamente acessível do nível de resistência em populações de $H$. contortus no campo (Höglund et al. 2009, Samson-Himmelstjerna et al. 2009b).

Muito embora não se tenham testes moleculares disponíveis para LMs, LEV ou tetra-hidropirimidinas em quaisquer espécies de parasitos, a base molecular da resistência para tais drogas recebe muita atenção e estudos. Foi relatado que quatro conjuntos de proteínas contribuem para a resistência ao LEV em Caenorhabditis elegans, sendo que o principal foco dos estudos para a expressão ou detecção de polimorfismos associados à resistência ao LEV em nematoides são os receptores de acetilcolina nicotínicos (nAChR) (Martin et al. 2012). Foi demonstrado que propriedades de ligação ao receptor de LEV em $H$. contortus não sofreram variação significativa com a resistência à droga e, 
a partir de análises de sequência e de RFLP em um gene nAChR (hca1) em várias populações de $H$. contortus resistentes ao LEV, foi observado polimorfismo, mas sem associação com a resistência (Hoekstra et al. 1997). Com relação às LMs, o mecanismo de resistência parece ser complexo, associado a muitas mutações em diferentes loci. Estudos sugerem que a resistência à IVM pode envolver alterações em transportadores de drogas, como a glicoproteína-P (P-gp, do inglês P-glycoprotein) e canais de cloro controlados pelo glutamato (Xu et al. 1998, Wolstenholme \& Rogers 2005). A resistência à IVM também tem sido associada a alterações alélicas no isotipo 1 do gene da $\beta$-tubulina, o locus chave envolvido na resistência aos BZs, e a proteínas associadas à resistência a múltiplas drogas (MRP, do inglês multi-drug resistance), juntamente com membros da família de transportadores do tipo ABC (do inglês ATP binding cassete) (Xu et al. 1998, Bourguinat et al. 2007, Prichard 2007).

Recentemente, o monepantel foi introduzido no mercado da Nova Zelândia como o primeiro membro da nova classe de drogas sintéticas nematocidas chamada Derivados de Amino Acetonitrila (AADs, do inglês Amino-Acetonitrile Derivatives). 0 alvo do monepantel (um nAChR específico de nematoide da subfamília DEG-3) e um conjunto de mutações associadas à sensibilidade reduzida a AADs em $H$. contortus também foram descritos (Kaminsky et al. 2008, Rufener et al. 2009b). Tais conhecimentos genéticos poderão ser úteis para o diagnóstico molecular da resistência. Contudo, como as mutações neste caso foram induzidas por seleção experimental, e enquanto não há isolados de parasitos de campo resistentes ao monepantel, não está claro se elas serão de importância prática (Demeler et al. 2012b).

Diagnóstico de resistência aos BZs em tricostrongilídeos. Como o teste de genotipagem de uma única larva ou verme adulto é muito trabalhoso e relativamente caro, os testes moleculares devem ser desenvolvidos para PCR em tempo real ou pirosequenciamento, a fim de torná-los adequados e viáveis ao uso na rotina laboratorial com amostras de campo. Somente com um diagnóstico baseado no uso de pool de amostras de DNA de larvas, será possível disponibilizar os testes de resistência molecular para uso rotineiro. A pesquisa para o desenvolvimento de testes moleculares pode ser justificável principalmente para espécies em que o problema da resistência é amplamente distribuído, além de auxiliar a busca por estratégias de manejo que possam retardar o desenvolvimento de resistência.

Para se iniciar o diagnóstico de resistência com amostras de campo, é feita a amplificação no isotipo 1 do gene da $\beta$-tubulina para obter uma quantidade suficiente de DNA, por meio de duas PCRs consecutivas (nested-PCR). Segue-se, então, com a identificação das espécies T. circumcincta, $H$. contortus e T. colubriformis, a partir da análise de polimorfismo nos locais de restrição da enzima RsaI no segmento amplificado desse gene, usando a técnica de RFLP. Esse método apresentou a vantagem de superar as limitações de identificação morfológica dos estágios larvais de espécies de nematoides (Coles et al. 2006). Larvas de $T$. colubriformis armazenadas por um mês a $4^{\circ} \mathrm{C}$ foram corretamente genotipadas, enquanto larvas de T. circumcincta mantidas em nitrogênio líquido foram menos eficientemente amplificadas. Assim, é recomendado o uso de larvas "frescas" para a obtenção de resultados confiáveis.

O princípio do diagnóstico de resistência aos BZs depende de um sistema de amplificação por mutação refratária (ARMS, do inglês Amplification Refractory Mutation System). Essa técnica permite a genotipagem de SNPs, usando um conjunto de quatro iniciadores (dois iniciadores não específicos - primers controle, e dois específicos de alelo primers internos), consistindo em uma reação de PCR alelo-específica (Fig. 2). Como mostra a referida figura, foram utilizados dois primers controles (forward e reverse) e dois primers internos específicos (um forward, que se liga a um alelo, e um reverse, que se liga ao outro alelo), resultando em três diferentes padrões de bandas (um controle e dois específicos). A concentração de iniciadores pode alterar a especificidade da PCR, e deve ser verificada com grande precisão, a fim de garantir uma eficiente competição entre os iniciadores. Isolados de parasitos reconhecidamente suscetíveis e resistentes devem ser utilizados como padrão e testados para validar a genotipagem de populações desconhecidas (Coles et al. 2006).

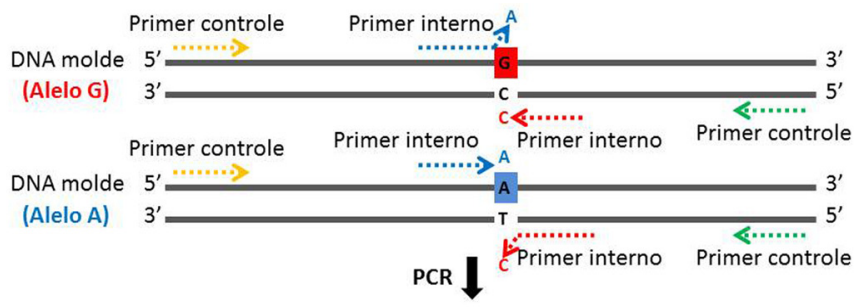

Produto - PCR

(Alelo inespecífico)

Produto - PCR

(Alelo G)
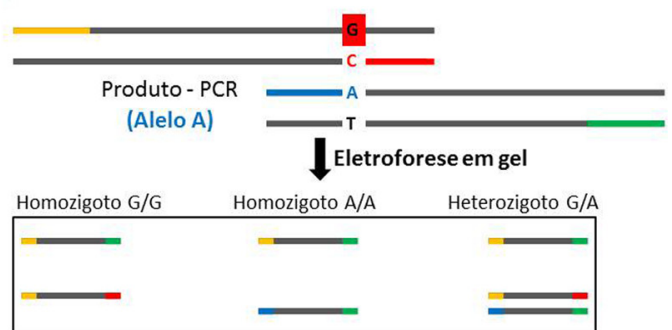

Fig.2. Genotipagem de SNPs pela técnica de PCR alelo-específica ou PCR baseada no sistema de amplificação por mutação refratária (ARMS) (Fortes 2011).

Foi determinado que o limite de detecção da resistência aos BZs, por meio de diagnóstico molecular, seja com um número de 100, 50, 35 e 20 parasitos para, respectivamente, $4,8,10$ e $12 \%$ de vermes resistentes na população, a fim de encontrar pelo menos um indivíduo resistente $(p=0,002)$ (Elard et al. 1999). Em uma população mista de nematoides, a frequência de alelos dependerá da proporção de espécies na população, e a identificação de genótipos resistentes homozigóticos em quaisquer espécies poderia sugerir a presença de resistência (Coles et al. 2006).

Ainda são poucas as informações de correlação entre a presença de mutações associadas à resistência e a eficácia de droga esperada, dificultando a interpretação clínica dos dados moleculares. Recentemente, Höglund et al. (2009) 
encontraram altas frequências alélicas associadas à resistência (códon 200 no isotipo 1 do gene da $\beta$-tubulina em H. contortus) em 19 rebanhos de ovinos dos 45 testados, enquanto o TRCOF detectou resistência ao albendazol em apenas dois rebanhos. Em três rebanhos cuja eficácia da droga pelo TRCOF foi de 100, 99 e 97\%, foram encontradas frequências muito altas de alelos resistentes de 95, 97 e $100 \%$. A disparidade nos resultados sugere ser muito difícil definir recomendações ideais para medidas de controle parasitário com base exclusivamente em dados moleculares (Kaplan \& Vidyashankar 2012).

Como mostrado, os testes moleculares parecem ser mais sensíveis que o TRCOF na detecção da presença de resistência anti-helmíntica em um rebanho. Mas o significado prático da resistência genotípica relacionada à eficácia esperada da droga, principalmente para produtos de um mesmo grupo, ainda não está claro. É comum a técnica de TRCOF detectar resistência a um anti-helmíntico e, ao mesmo tempo, alta eficácia a outro do mesmo grupo. Uma vez que marcadores moleculares de resistência aos BZs não são específicos de uma só droga, o uso de dados moleculares para a escolha de drogas a serem utilizadas no campo ainda exige uma maior compreensão (Kaplan \& Vidyashankar 2012). Os autores discutiram ainda outros pontos críticos: quando a resistência a um grupo de drogas é multi-alélica, torna-se necessário conhecer a contribuição relativa de cada alelo para a manifestação do fenótipo; a resistência a qualquer droga é espécie-específica, mas as infecções mistas nos animais são muito comuns, sendo necessário o desenvolvimento de testes moleculares capazes de detectar resistência em múltiplas espécies, ou testes separados para as espécies importantes.

A grande dificuldade para o diagnóstico com base molecular, é ter a certeza de que a mutação associada a resistência à determinada droga seja a única mutação responsável em uma espécie particular. Esse desafio pode ser exemplificado pela existência de mais de um ponto de mutação de resistência aos BZs em certos nematoides de ovinos. No caso das LMs, se as diferentes espécies de nematoides têm diferentes mecanismos para impedir a ação das drogas, a dificuldade para o desenvolvimento e a utilização de testes torna-se ainda maior. No entanto, como não há nenhum teste in vitro de confiabilidade reconhecida para a resistência às LMs, a necessidade de testes moleculares é muito grande (Coles et al. 2006).

\section{CONSIDERAÇÕES FINAIS}

A maioria das estratégias de controle de nematoides gastrintestinais empregadas em criações intensivas de ovinos e caprinos ainda depende do frequente uso de anti-helmínticos. No entanto, o grande número de relatos de parasitos resistentes a um ou mais anti-helmínticos utilizados vem inviabilizando os programas de controle sanitário. É evidente a necessidade de adoção de estratégias sustentáveis, incluindo o controle químico, ambiental e imunológico, visando substituir os esquemas baseados no uso exclusivo de anti-helmínticos, para diminuir a pressão de seleção na população de parasitos. Novos conceitos, como a manutenção da população de parasitos em refugia, não expostos a anti-helmínticos, obtida principalmente com o uso de tratamento seletivo dos animais, precisam ser amplamente difundidos entre produtores e profissinais da área.

Como visto, a rapidez com que ocorre a propagação da resistência anti-helmíntica, com o comércio de animais, é preocupante e reforça a necessidade urgente de testes diagnósticos sensíveis e economicamente acessíveis para a detecção e o monitoramento da resistência. Devido ao grande impacto que a resistência possui em relação à produção e ao bem-estar de pequenos ruminantes, torna-se cada vez mais importante o seu diagnóstico preciso e precoce. Faz-se necessário aprimorar os métodos conhecidos às condições dos produtores, com a inclusão de testes para detectar a resistência na rotina de programas sanitários, como o TRCOF. Para isso, uma série de testes in vitro ainda precisa ser padronizada, a fim de permitir sua correta execução e interpretação em diferentes laboratórios. Infelizmente, os esforços para a obtenção do diagnóstico da resistência anti-helmíntica e a conscientização de profissionais da área acerca desse problema ainda são insuficientes.

Espera-se que o uso crescente de modernas técnicas de sequenciamento genômico (o genoma completo do $H$. contortus será publicado em breve, Beech 2013) propicie avanços na compreensão do mecanismo molecular (ou mecanismos moleculares) da resistência anti-helmíntica, permitindo o aprimoramento de técnicas de monitoramento rápido. A obtenção de um diagnóstico da resistência mais precoce e acessível no campo pode auxiliar a tomada de decisão quanto à escolha do tipo de estratégia de controle parasitário a ser utilizado. Para isso, é extremamente importante haver orientação profissional adequada aos produtores sobre o uso racional de anti-helmínticos, buscando manter a eficácia das drogas e retardar o fenômeno da resistência. Recomenda-se que, tanto o pesquisador como o profissional ligado à área de sanidade, tenha interesse na leitura das recomendações técnicas. Deve-se utilizar o TRCOF uma vez ao ano, com o objetivo de monitorar a eficácia, e substituir produtos que apresentem percentuais abaixo de $80 \%$. Espera-se que, com isso, possa-se contribuir para a sustentabilidade da pecuária nacional, visando obter melhores condições de saúde, tanto para os animais como para a comunidade.

Agradecimentos.- À Coordenação de Aperfeiçoamento de Pessoal de Nível Superior (CAPES/REUNI), pela concessão de bolsa de doutorado à Fernanda S. Fortes.

\section{REFERÊNCIAS}

Almeida G.D., Feliz D.C., Heckler R.P., Borges D.G.L., Onizuka M.K.V., Tavares L.E.R., Paiva F. \& Borges F.A. 2013. Ivermectin and moxidectin resistance characterization by larval migration inhibition test in field isolates of Cooperia spp. in beef cattle, Mato Grosso do Sul, Brazil. Vet. Parasitol. 191:59-65.

Alvarez-Sanchez M.A., Perez Garcia J., Bartley D., Jackson F. \& Rojo-Vazquez F.A. 2005. The larval feeding inhibition assay for the diagnosis of nematode anthelmintic resistance. Exp. Parasitol. 110:56-61.

Barrère V., Alvarez L., Suarez G., Ceballos L., Moreno L., Lanusse C. \& Prichard R.K. 2012. Relationship between increased albendazole systemic exposure and changes in single nucleotide polymorphisms on the $\beta$-tubulin isotype 1 encoding gene in Haemonchus contortus. Vet. Parasitol. 186:344-349. 
Beech R. 2013. Comunicação pessoal (Institute of Parasitology, McGill University, Canada).

Bourguinat C., Pion S.D.S., Kamgno J., Gardon J., Duke B.O.L., Boussinesq M. \& Prichard R.K. 2007. Genetic selection of low fertile Onchocerca volvulus by ivermectin treatment. PLoS Negl. Trop. Dis. 1:1-11.

Calvete C., Calavia R., Ferrer L.M., Ramos J.J., Lacasta D. \& Uriarte J. 2011. Management and environmental factors related to benzimidazole resistance in sheep nematodes in Northeast Spain. Vet. Parasitol. 23:193203.

Cezar A.S., Toscan G., Camillo G., Sangioni L.A., Ribas H.O. \& Vogel F.S.F. 2010. Multiple resistance of gastrointestinal nematodes to nine different drugs in a sheep flock in southern Brazil. Vet. Parasitol. 173:157160.

Chagas A.C.S., Niciura S.C.M. \& Molento M.B. 2011. Manual Prático: metodologias de diagnóstico da resistência e de detecção de substâncias ativas em parasitas de ruminantes. Embrapa Informação Tecnológica, Brasília, DF. 153p.

Chagas A.C.S., Katiki L.M., Silva I.C., Giglioti R., Esteves S.N., Oliveira M.C.S. \& Barioni Júnior W. 2013. Haemonchus contortus: A multiple-resistant Brazilian isolate and the costs for its characterization and maintenance for research use. Parasitol. Int. 62:1-6.

Coles G.C., Tritschler J.J. II, Giordano D.J., Laste N.J. \& Schmidt A.L. 1988. A larval development test for detection of anthelmintic resistant nematodes. Res. Vet. Sci. 45:50-53.

Coles G.C., Bauer C., Borgsteede F.H.M., Geerts S., Klei T.R., Taylor M.A. \& Waller P.J. 1992. World Association for the Advancement of Veterinary Parasitology (WAAVP) methods for the detection of anthelmintic resistance in nematodes of veterinary importance. Vet. Parasitol. 44:35-44.

Coles G.C., Jackson F., Pomroy W.E., Prichard R.K., Samson-Himmelstjerna G., Silvestre A., Taylor M.A. \& Vercruysse J. 2006. The detection of anthelmintic resistance in nematodes of veterinary importance. Vet. Parasitol. 136:167-185

Demeler J., Kuttler U. \& Samson-Himmelstjerna G. 2010. Adaptation and evaluation of three different in vitro tests for the detection of resistance to anthelmintics in gastro intestinal nematodes of cattle. Vet. Parasitol. 170:61-70.

Demeler J., Kleinschmidt N., Küttler U., Koopmann R. \& Samson-Himmelstjerna G. 2012a. Evaluation of the Egg Hatch Assay and the Larval Migration Inhibition Assay to detect anthelmintic resistance in cattle parasitic nematodes on farms. Vet. Parasitol. 61:614-618.

Demeler J., Schein E. \& Samson-Himmelstjerna G. 2012b. Advances in laboratory diagnosis of parasitic infections of sheep. Vet. Parasitol. 189:52-64.

Díez-Baños P., Pedreira J., Sánchez-Andrade R., Francisco I., Suárez J.L., Díaz P., Panadero R., Arias M., Painceira A., Paz-Silva A. \& Morrondo P. 2008. Field evaluation for anthelmintic-resistant ovine gastrointestinal nematodes by in vitro and in vivo assays. J. Parasitol. 94:925-928.

Dobson R.J., Hosking B.C., Jacobson C.L., Cotter J.L., Besier R.B., Stein P.A. \& Reid S.A. 2012. Preserving new anthelmintics: A simple method for estimating faecal egg count reduction test (FECRT) confidence limits when efficacy and/or nematode aggregation is high. Vet. Parasitol. 186:79-92.

Dolinská M., Königová Alzbeta \& Várady M. 2012. Is the micro-agar larval development test reliable enough to detect ivermectin resistance? Parasitol. Res. 111:2201-2204.

Douch P.G. \& Morum P.E. 1994. The effects of anthelmintics on ovine larval nematode parasite migration in vitro. Int. J. Parasitol. 24:321-326.

Elard L., Comes A.M. \& Humbert J.F. 1996. Sequences of beta-tubulin cDNA from benzimidazole-susceptible and -resistant strains of Teladorsagia circumcincta, a nematode parasite of small ruminants. Mol. Biochem. Parasitol. 79:249-253.

Elard L., Cabaret J. \& Humbert J.F. 1999. PCR diagnosis of benzimidazolesusceptibility or -resistance in natural populations of the small ruminant parasite, Teladorsagia circumcincta. Vet. Parasitol. 80:231-237.

Folz S.D., Pax R.A., Thomas E.M., Bennett J.L., Lee B.L. \& Conder G.A. 1987. Motility response of benzimidazole-resistant Haemonchus contortus lar- vae to several anthelmintics. Proc. Helminthol. Soc. Washington 54:249253.

Fortes F.S. 2011. Marcadores moleculares SNP: conceitos e aplicações na resistência anti-helmíntica, p.83-91. In: Chagas A.C.S., Niciura S.C.M. \& Molento M.B. 2011. Manual Prático: metodologias de diagnóstico da resistência e de detecção de substâncias ativas em parasitas de ruminantes. Embrapa Informação Tecnológica, Brasília, DF.

Fortes F.S., Kloster F.S., Schafer A.S., Bier D., Buzatti A., Yoshitani U.Y. \& Molento M.B. 2013. Evaluation of resistance in a selected field strain of Haemonchus contortus to ivermectin and moxidectin using the Larval Migration on Agar Test. Pesq. Vet. Bras. 33(2):183-187

Geary T. 2013 Comunicação pessoal (Institute of Parasitology, McGill University, Canada).

Ghisi M., Kaminsky R. \& Maser P. 2007. Phenotyping and genotyping of Haemonchus contortus isolates reveals a new putative candidate mutation for benzimidazole resistance in nematodes. Vet. Parasitol. 144:313320.

Gill J.H. \& Lacey E. 1998. Avermectin/milbemycin resistance in trichostrongyloid nematodes. Int. J. Parasitol. 28:863-877.

Gill J.H., Redwin J.M., Van Wyk J.A. \& Lacey E. 1991. Detection of resistance to ivermectin in Haemonchus contortus. Int. J. Parasitol. 21:771-776.

Gill J.H., Redwin J.M., Van Wyk J.A. \& Lacey E. 1995. Avermectin inhibition of larval development in Haemonchus contortus-effects of ivermectin resistance. Int. J. Parasitol. 25:463-470.

Hart E.H., Morphew R.M., Bartley D.J., Millares P., Wolf B.T., Brophy P.M. \& Hamilton J.V. 2012. The soluble proteome phenotypes of ivermectin resistant and ivermectin susceptible Haemonchus contortus females compared. Vet. Parasitol. 190:104-113.

Hoekstra R., Visser A., Wiley L.J., Weiss A.S., Sangster N.C. \& Roos M.H. 1997. Characterisation of an acetylcholine receptor gene of Haemonchus contortus in relation to levamisole resistance. Mol. Biochem. Parasitol. 84:179-187.

Höglund J., Gustafsson K., Ljungström B.L., Engström A., Donnan A. \& Skuce P. 2009. Anthelmintic resistance in Swedish sheep flocks based on a comparison of the results from the faecal egg count reduction test and resistant allele frequencies of the beta-tubulin gene. Vet. Parasitol. 161:60-68.

Hubert J. \& Kerboeuf D. 1992. A microlarval development assay for the detection of anthelmintic resistance in sheep nematodes. Vet. Rec. 130:442-446.

Kaminsky R., Ducray P., Jung M., Clover R., Rufener L., Bouvier J., Weber S.S., Wenger A., Wieland-Berghausen S., Goebel T., Gauvry N., Pautrat F., Skripsky T., Froelich O., Komoin-Oka C., Westlund B., Sluder A. \& Mäser P. 2008. A new class of anthelmintics effective against drug resistant nematodes. Nature. 452:176-180.

Kaplan R.M. \& Vidyashankar A.N. 2012. An inconvenient truth: Global worming and anthelmintic resistance. Vet. Parasitol. 186:70-78.

Kerboeuf D., Chambrier P., Vern Y.l. \& Aycardi J. 1999. Flow cytometry analysis of drug transport mechanisms in Haemonchus contortus susceptible or resistant to anthelmintics. Parasitol. Res. 85:118-123.

Kotze A.C., Le Jambre L.F. \& O'Grady J. 2006. A modified larval migration assay for detection of resistance to macrocyclic lactones in Haemonchus contortus, and drug screening with Trichostrongylidae parasites. Vet. Parasitol. 137:294-305.

Kwa M.S.G., Veenstra J.G. \& Roos M.H. 1994. Benzimidazole resistance in Haemonchus contortus is correlated with a conserved mutation at amino acid 200 in beta-tubulin isotype 1. Mol. Biochem. Parasitol. 63:299303.

Kwa M.S.G., Veenstra J.G., Dijk M.V. \& Roos M.H. 1995. Beta-tubulin genes from the parasitic nematode Haemonchus contortus modulate drug resistance in Caenorhabditis elegans. J. Mol. Biol. 246:500-510.

Leathwick D.M., Miller C.M., Atkinson D.S., Haack N.A., Alexander R.A., Oliver A.M., Waghorn T.S., Potter J.F. \& Sutherland I.A. 2006. Drenching adult ewes: implications of anthelmintic treatments pre- and postlambing on the development of anthelmintic resistance. N. Z. Vet. J. 54:297-304. 
Levecke B., Dobson R.J., Speybroeck N., Vercruysse J. \& Charlier J. 2012. Novel insights in the faecal egg count reduction test for monitoring drug efficacy against gastrointestinal nematodes of veterinary importance. Vet. Parasitol. 188:391-396.

Little P.R., Hodges A., Watson T.G., Seed J.A. \& Maeder S.J. 2010. Field efficacy and safety of an oral formulation of the novel combination anthelmintic, derquantel-abamectin, in sheep in New Zealand. N. Z. Vet. J. 58:121-129.

Love S.J.C. \& Coles G.C. 2002. Anthelmintic resistance in sheep worms in New South Wales, Australia. Vet. Rec. 150:87.

Martin P.J. \& LeJambre L.F. 1979. Larval paralysis test as an in vitro assay of levamisole and morantel tartrate resistance in Ostertagia. Vet. Sci. Commun. 3:159-164.

Martin P.J., Anderson N. \& Jarrett R.G. 1985. Resistance to benzimidazole anthelmintics in field strains of Ostertagia and Nematodirus in sheep. Aust. Vet. J. 62:38-43.

Martin P.J., Anderson N. \& Jarrett R.G. 1989. Detecting benzimidazole resistance with faecal egg count reduction tests and in vitro assays. Aust. Vet. J. 66:236-240.

Martin R.J., Robertson A.P., Buxton S.K., Beech R.N., Charvet C.L. \& Neveu C. 2012. Levamisole receptors: a second awakening. Trends Parasitol. 28:289-296.

Martínez-Valladares M., Famularo M.R., Fernández-Pato N., Cordero-Pérez C., Castañón-Ordóñez L. \& Rojo-Vázquez F.A. 2012. Characterization of a multidrug resistant Teladorsagia circumcincta isolate from Spain. Parasitol. Res. 110:2083-2087.

Martínez-Valladares M., Martínez-Pérez J.M., Robles-Pérez D., Cordero-Pérez C., Famularo M.R., Fernández-Pato N., Castañón-Ordóñez L. \& Rojo-Vázquez F.A. 2013. The present status of anthelmintic resistance in gastrointestinal nematode infections of sheep in the northwest of Spain by in vivo and in vitro techniques. Vet. Parasitol. 191:177-181.

McKenna P.B. 1998. The effect of previous cold storage on the subsequent recovery of infective third stage nematode larvae from sheep faeces. Vet. Parasitol. 89:167-172.

McKenna P.B. 2010. Update on the prevalence of anthelmintic resistance in gastrointestinal nematodes of sheep in New Zealand. N. Z. Vet. J. 58:172-173.

Miller C.M., Waghorn T.S., Leathwick D.M. \& Gilmour M.L. 2006. How repeatable is a faecal egg count reduction test? N. Z. Vet. J. 54:323-328.

Molento M.B. \& Prichard R.K. 2001. Effect of multigrug resistance modulators on the activity of ivermectin and moxidectin against selected strains of Haemonchus contortus infective larvae. Pesq. Vet. Bras. 21:117-121.

Molento M.B., Fortes F.S., Pondelek D.A.S., Borges F.A., Chagas A.C.S., Torres-Acosta J.F.J. \& Geldhof P. 2011. Challenges of nematode control in ruminants: Focus on Latin America. Vet. Parasitol. 180:126-132.

Molento M.B., Fortes F.S. \& Kloster F.S. 2012. Diagnóstico da resistência anti-helmíntica com a utilização de métodos coproparasitológicos. Anais XVII Congr. Bras. Parasitol. Vet., São Luís, MA, p.15-16.

Mottier M.L. \& Prichard R.K. 2008. Genetic analysis of a relationship between macrocyclic lactone and benzimidazole anthelmintic selection on Haemonchus contortus. Pharmacogenet. Genomics 18:129-140.

Palcy C., Silvestre A., Sauve C., Cortet J. \& Cabaret J. 2010. Benzimidazole resistance in Trichostrongylus axei in sheep: long-term monitoring of affected sheep and genotypic evaluation of the parasite. Vet. Journal 183:68-74.

Papadopoulos E., Gallidis E. \& Ptochos S. 2012. Anthelmintic resistance in sheep in Europe: A selected review. Vet. Parasitol. 189:85-88.

Prichard R. 2007. Ivermectin resistance and overview of the consortium for anthelmintic resistance SNPs. Expert Opin. Drug Discov. 2(Suppl. 1): S41-S52.

Rinaldi L., Coles G.C., Maurelli M.P., Musella V. \& Cringoli G. 2011. Calibration and diagnostic accuracy of simple flotation, McMaster and FLOTAC for parasite egg counts in sheep. Vet. Parasitol. 177:345-352.

Roberts F.H.S. \& O'Sullivan J.P. 1950. Methods for egg count and larval cultures for strongyles infesting the gastro-intestinal tract of cattle. Aust. J. Agr. Res. 1:99-102.
Roberts J.L. \& Swan R.A. 1981. Quantitative studies of ovine haemonchosis. I. Relationship between faecal egg counts and total worm counts. Vet. Parasitol. 8:165-171.

Roeber F., Larsen J.W.A., Anderson N., Campbell A.J.D., Anderson G.A., Gasser R.B. \& Jex A.R. 2012. A molecular diagnostic tool to replace larval culture in conventional faecal egg count reduction testing in sheep. PLoS ONE 7(5):e37327. doi:10.1371/journal.pone.0037327

Rufener L., Kaminsky R. \& Mäser P. 2009a. In vitro selection of Haemonchus contortus for benzimidazole resistance reveals a mutation at amino acid 198 of beta-tubulin. Mol. Biochem. Parasitol. 168:120-122.

Rufener L., Mäser P., Roditi I. \& Kaminsky R. 2009b. Haemonchus contortus acetylcholine receptors of the DEG-3 subfamily and their role in sensitivity to monepantel. PLoS Pathog. 5(4):e1000380. doi: 10.1371/journal.ppat. 1000380

Samson-Himmelstjerna G. 2006. Molecular diagnosis of anthelmintic resistance. Vet. Parasitol. 136:99-107.

Samson-Himmelstjerna G., Harder A. \& Scnieder T. 2002. Quantitative analysis of ITS2 sequences in trichostrongyle parasites. Int. J. Parasitol. 32:1529-1535.

Samson-Himmelstjerna G., Blackhall W.J., McCarthy J.S. \& Skuce P.J. 2007. Single nucleotide polymorphism (SNP) markers for benzimidazole resistance in veterinary nematodes. Parasitology 134:1077-1086.

Samson-Himmelstjerna G., Coles G.C., Jackson F., Bauer C., Borgsteede F., Cirak V.Y., Demeler J., Donnan A., Dorny P., Epe C., Harder A., Hoglund J., Kaminsky R., Kerboeuf D., Kuttler U., Papadopoulos E., Posedi J., Small J., Varady M., Vercruysse J. \& Wirtherle N. 2009a. Standardization of the egg hatch test for the detection of benzimidazole resistance in parasitic nematodes. Parasitol. Res. 105:825-834.

Samson-Himmelstjerna G., Walsh T.K., Donnan A.A., Carrière S., Jackson F., Skuce P.J., Rohn K. \& Wolstenholme A.J. 2009b. Molecular detection of benzimidazole resistance in Haemonchus contortus using real-time PCR and pyrosequencing. Parasitology 136:349-358.

Sangster N.C., Whitlock H.V., Russ I.G., Gunawan M., Griffin D.L. \& Kelly J.D. 1979. Trichostrongylus colubriformis and Ostertagia circumcincta resistant to levamisole, morantel tartrate and thiabendazole: occurrence of field strains. Res. Vet. Sci. 27:106-110.

Shayan P., Eslami A. \& Borji H. 2007. Innovative restriction site created PCR-RFLP for detection of benzimidazole resistance in Teladorsagia circumcincta. Parasitol. Res. 100:1063-1068.

Sczesny-Moraes E.A., Bianchin I., Silva K.F., Catto J.B., Honer M.R. \& Paiva F. 2010. Resistência anti-helmíntica de nematoides gastrointestinais em ovinos, Mato Grosso do Sul. Pesq. Vet. Bras. 30:229-236.

Silvestre A. \& Humbert J.F. 2000. A molecular tool for species identification and benzimidazole resistance diagnosis in larval communities of small ruminant parasites. Exp. Parasitol. 95:271-276.

Silvestre A. \& Cabaret J. 2002. Mutation in position 167 of isotype 1 betatubulin gene of trichostrongylid nematodes: role in benzimidazole resistance? Mol. Biochem. Parasitol. 120:297-300.

Sutherland I.A. \& Lee D.L. 1990. A larval paralysis assay for the detection of thiabendazole resistance in trichostrongyles. Parasitology 100:131135.

Taylor M.A., Hunt K.R. \& Goodyear K.L. 2002. Anthelmintic resistance detection methods. Vet. Parasitol. 103:183-194.

Tiwari J., Kumar S., Kolte A.P., Swarnkar C.P., Singh D. \& Pathak K.M. 2006. Detection of benzimidazole resistance in Haemonchus contortus using RFLP-PCR technique. Vet. Parasitol. 138:301-307.

Torres-Acosta J.F.J., Mendoza-de-Gives P., Aguilar-Caballero A.J. \& Cuéllar-Ordaz J.A. 2012. Anthelmintic resistance in sheep farms: Update of the situation in the American continent. Vet. Parasitol. 189:89-96.

Ueno H. \& Gonçalves P.C. 1998. Manual para Diagnóstico das Helmintoses de Ruminantes. $4^{\mathrm{a}}$ ed. Press Color, Salvador. 143p.

Van Wyk J.A., Stenson S.O., Van der Mrewe J.S., Vordsetr R.J. \& Vilijoen P.G. 1999. Anthelmintic resistance in South Africa: surveys indicate an extremely serious situation in sheep and goat farming. Onderstepoort J. Vet. Res. 66:273-284.

Várady M., Cernanská D. \& Corba J. 2006. Use of two in vitro methods for 
the detection of anthelmintic resistant nematode parasites on Slovak sheep farms. Vet. Parasitol. 135:325-331.

Veríssimo C.J., Niciura S.C.M., Alberti A.L.L., Rodrigues C.F.C., Barbosa C.M.P., Chiebao D.P., Cardoso D., da Silva G.S., Pereira J.R., Margatho L.F.F., da Costa R.L.D., Nardon R.F., Ueno T.E.H., Curci V.C.L.M. \& Molento M.B. 2012. Multidrug and multispecies resistance in sheep flocks from São Paulo state, Brazil. Vet. Parasitol. 187:209-216.

Wagland B.M., Jones W.O., Hribar L., Bendixsen T. \& Emery D.L. 1992. A new simplified assay for larval migration inhibition. Int. J. Parasitol. 22:1183-1185.

Wolstenholme A.J. \& Rogers AT. 2005. Glutamate-gated chloride channels and the mode of action of the avermectin/milbemycin anthelmintics. Parasitology 131 (Suppl.):S85-S95.

Xu M., Molento M., Blackhall W., Ribeiro P., Beech R. \& Prichard R. 1998. Ivermectin resistance in nematodes may be caused by alteration of $\mathrm{P}$ glycoprotein homolog. Mol. Biochem. Parasitol. 91:327-335. 